\title{
The Evolution of Theory of Mind in the Human Evolution
}

\section{Dingyu Chung}

Utica, MI, USA

Email: dy_chung@yahoo.com

How to cite this paper: Chung, D.Y. (2021) The Evolution of Theory of Mind in the Human Evolution. Journal of Behavioral and Brain Science, 11, 10-26. https://doi.org/10.4236/jbbs.2021.111002

Received: December 1, 2020

Accepted: January 11, 2021

Published: January 14, 2021

Copyright $\odot 2021$ by author(s) and Scientific Research Publishing Inc. This work is licensed under the Creative Commons Attribution International License (CC BY 4.0).

http://creativecommons.org/licenses/by/4.0/ (c) (i) Open Access

\begin{abstract}
Despite almost half a century of research for theory of mind, its evolutionary origin is largely unknown. This paper proposes that the evolutionary origin of theory of mind starts from the beginning of the human evolution to form hominins through bipedalism and the mixed habitat. The feet of the early hominins were still adapted for grasping trees rather than walking for long distances and running fast on the ground. The early hominins lived in the mixed habitat of grassy woodland with patches of denser forest, and freshwater springs. The difficulty of walking in the mixed habitat leads to division of labor for the home specialist group (small children, old people, and mothers with small children, and pregnant women) in the safe forest area and the exploration specialist group (young people without the care of small children) in the dangerous open area. The different tasks, attitudes, and mentalities in different specialist groups produce theory of mind as the ability to attribute different mental states to different specialist groups. (Uniformity of mind instead of theory of mind is for generalists without division of labor). The early Homo species with the open habitat developed theory of mind for hunter specialist group and gatherer specialist group. The middle Homo species with complex stone tools developed theory of mind for the cooperative specialist groups in the large production of complex stone tools. The late Homo species with complex social interaction developed theory of mind for mind reading to enhance cooperation and to detect cheaters in complex social interaction. For religion, the unusually harsh Upper Paleolithic Period developed theory of mind for imaginary specialists in terms of supernatural power, guidance, and comfort. Therefore, the three general types of theory of mind are for specialists in division of labor, mind reading in complex social interaction, and imaginary specialists in imaginary division of labor under harsh conditions. Self-awareness in the mirror self-recognition test is also explained.
\end{abstract}

\section{Keywords}

Theory of Mind, Human Evolution, Evolution of Theory of Mind, Religion, 
Self-Awareness, Mirror Self-Recognition Test

\section{Introduction}

Theory of mind is the ability to attribute mental states including beliefs, intents, desires, emotions, and knowledge to ourselves and others. Only humans have robust theory of mind [1]. Having a theory of mind allows us to understand that others have unique beliefs and desires that are different from our own, enabling us to engage in daily social interaction as we interpret the mental states and infer the behaviors of those around us [2]. The opposite of theory of mind is uniformity of mind where others have same beliefs and desires as our own. However, despite almost half a century of research, its evolutionary origin is largely unknown [3].

Since only humans have robust theory of mind, it is possible that theory of mind is originated at the very beginning of the hominin evolution to form hominins separated from chimpanzees that have no theory of mind. As a result, this paper chooses the literatures based on theory of mind and the human evolution that starts from the hominins separated from chimpanzees. This paper purposes that the combination of bipedalism and the mixed habitat at the beginning of the hominin evolution results in division of labor that produces theory of mind [4]. The feet of the early hominins were still adapted for grasping trees rather than walking for long distances and running fast on the ground [5]. The early hominins lived in the mixed habitat of grassy woodland with patches of denser forest, and freshwater springs. The difficulty of walking in the mixed habitat leads to division of labor for the home specialist group (small children, old people, and mothers with small children, and pregnant women) in the safe forest area and the exploration specialist group (young people without the care of small children) in the dangerous open area. The different tasks, attitudes, and mentalities in different specialist groups produce theory of mind as the ability to attribute different mental states to different specialist groups. (Uniformity of mind instead of theory of mind is for generalists without division of labor).

The early Homo species [6] with the open habitat developed theory of mind for hunter specialist group and gatherer specialist group. The middle Homo species [7] with complex stone tools produced theory of mind for the cooperative specialist groups in the large production of complex stone tools. The late Homo species with complex social interaction developed theory of mind for mind reading to enhance cooperation and to detect cheaters in complex social interaction [8]. For religion, the unusually harsh Upper Paleolithic Period developed theory of mind for imaginary specialists in terms of supernatural power, guidance, and comfort in imaginary division of labor under harsh condition. [9]. Therefore, the three general types of theory of mind are for specialists in division of labor, mind reading in complex social interaction, and imaginary specialists in imaginary division of labor under harsh condition. The evolution of theory of mind is described in Figure 1. 


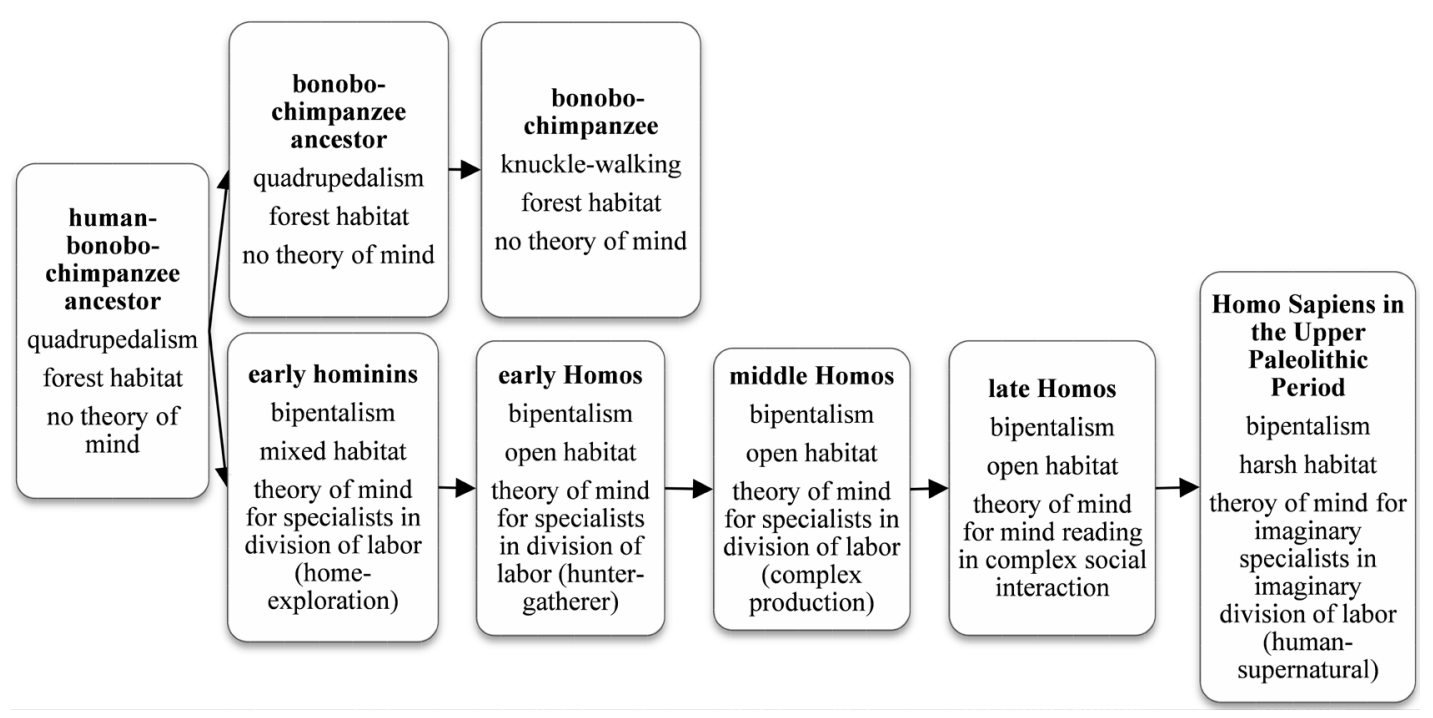

Figure 1. The evolution of theory of mind and the types of theory of mind.

Section 2 describes the early hominins. Section 3 explains the Homo species. Section 4 discuses Homo sapiens in the Upper Paleolithic Period. Section 5 explains theory of mind model. Section 6 explains the model for self-awareness in the Mirror Self-Recognition (MSR) Test.

\section{The Early Hominins}

Around 6 millions of years ago, a major climate change reduced some part of forested area in Africa to woodland where Ardi (Ardipithecus ramidus) [5] was evolved. Ardi, the oldest human ancestor (4.4 million years old) discovered, lived in the mixed habitat. Similar to other apes, Ardi's skull encased a small brain -300 to $350 \mathrm{cc}$. She lived in the mixed habitat of grassy woodland with patches of denser forest, and freshwater springs. The appearance of woodland caused the evolution from the social orangutan-like common ancestor to produce the bipedal human ancestors, the early hominins. Woodland allowed increasingly amount of food from bushes and low branches, which could be seen and reached from the ground. According to the observation [10] in Africa, chimpanzees today move on two legs most often when feeding on the ground from bushes and low branches. When food resources are scarce or unpredictable, chimpanzees use upright locomotion to improve food carrying efficiency. It suggests that the same might have occurred among the early hominins. Comparing to forest area, woodland area had scarcer food resources.

For reaching food from low branches on woodland and to carry food, the early hominins came down to the ground partly (not entirely) from living among trees, and adopted bipedalism as the way to move on the ground. However, Ardi's foot was primitive with an opposable big toe that could not provide a push needed for efficient bipedal walking. Ardi had a more primitive walking ability than later hominins, and Ardi had a somewhat awkward gait when on the ground. Its feet were still adapted for grasping trees rather than walking for long dis- 
tances and running fast on the ground. (For apes, the quadrupedal knuckle-walking like gorillas, bonobos, and chimpanzees was faster and better way than Ardi's primitive awkward bipedalism to move on the ground.) The movement handicap of bipedalism on the ground was serious for very young, very old, and pregnant early hominins. To the early hominins in the mixed habitats, the area with many tall trees was the safe home area where very young, very old, and pregnant hominins stayed, and where they could escape quickly to the safety in tall trees, and the area with few tall trees was the unsafe exploration area for the exploration to find extra foods that could not be found in the safe home area. The two free hands from bipedalism allowed the early hominins to carry a large quantity of food home from the exploration as proposed by C. Owen Lovejoy [11] and to carry simple defensive weapons such as sticks and stones to defense against large predators in the unsafe open area. The exploration also allowed them to scavenge meats left by carnivores. Consequently, the bipedalism and the mixed habitat divided the early hominins into the home hominins who stayed in the safe home area and the exploration hominins who explored in the unsafe exploration area during daytime and return home at night. The specialist groups are the home specialist group and the exploration specialist group for division of labor [4].

The home specialist group was the homemaker-forager who took care of children and foraged in the safe forest home area. The exploration specialist group is the explorer-forager who explored and foraged in the unsafe open exploration area. A good home specialist was able to do multitask and navigate through landmarks (different trees) as women today. A good exploration specialist was able to have a good sense of direction (orientation in space) for exploration and strong upper body strength to carry foods and defensive weapons as men today.

The home specialists evolved into fertile and infertile home specialists. Women today become infertile after menopause at about the age of 51. A today woman's best reproductive years are in her 20s. Fertility gradually declines in the 30 s, particularly after age 35 . Infertile home specialists took care of their grandchildren, so fertile home specialists could have babies frequently.

The home specialist group and the exploration specialist group were interdependent in terms of existential division of labor. The interdependent specialists were derived from the mixed habitat and the bipedalism which initially produced two hand-like primitive soft feet and two free hands, resulting in the movement handicap (awkward walking) and the capability in carrying large quantities of foods home by free hands from the long distance forgers. The division of labor allowed the early specialist groups to take full advantage of the mixed habitat in terms of security and food procurement.

The human gesture language was enhanced by the free hands as sign language. Learning simple sign language does not require a large brain. Chimpanzee Washoe learned approximately 350 words of American Sign Language [12]. She was able to communicate with humans in sign language sentences, and there was no 
significant difference in quality between her use of gestural language and the use of ordinary speech by children. The free hands allowed the early hominins to communicate in sign language extensively in most occasions, especially during forages when the continuous communication among the members in a forage group was important. Gestural communication served as a stepping stone for the evolution of human verbal communication. Gesture production in humans is so automatic that it is relatively immune to audience effects: blind subjects gesture at equal rates as sighted subjects to a known blind audience. Gestural communication as gestural language is the predecessor of spoken language [13]. The generally right-handed dominant hominin caused the development of the gestural language area (Broca's area) in the left-brain that eventually developed into the part for the spoken language later. Broca's area can be seen in endocasts from the early hominins Australopithecus. In the study by Hickok, Bellugi and Klima [14], the impairment for sign language patients was identical with that of speaking patients. At the hemispheric level, the neural organization of sign language is indistinguishable from that of spoken language. The gestural communication by the free hands enhanced harmony. The two important traits that distinguish early hominins from other apes are bipedalism and small canine teeth. Early hominins lost the large sharp canine teeth for continuous internal aggression and fighting that took place in some other apes.

Other apes evolved with different ways other than bipedalism to survive. For orangutan in dense rainforest, the feet are much more useful to climb trees than to walk on the ground, so orangutan did not develop bipedalism for walking. Gorillas, chimpanzees and bonobos who live in forest area did not develop bipedalism, because they needed fast and steady quadrupedal knuckle walking with the knuckle hands to escape from predators and for the large foraging ranges on the ground. The bipedalism of the early hominins evolved before the quadrupedal knuckle walking [15].

Such interdependent specialists groups with good gestural communication produced theory of mind that recognizes that the others exist to think for themselves. The different tasks, attitudes, and mentalities in different specialist groups produce theory of mind as the ability to attribute different mental states to different specialist groups. Theory of mind is derived from theory of specialty in interdependent specialists group where each specialist has its own specialty of work and work plan. In theory of specialist, each specialist must recognize that each specialist has its own specialty different from the specialties of other specialists, and each specialist has its own work plan distinctively different from the work plans of other specialists. To work together interdependently, all specialists must have theory of specialist in order to avoid overlapping unproductively and dangerously each other's work. The opposite of theory of mind is uniformity of mind for generalist, each generalist does not need to distinctively recognize the types of work and work plans of other generalists, because they are not distinctively different. 


\section{The Homo Species}

The early hominins developed later much better feet to overcome the initial movement handicap on the ground, but the early hominins continued to retain the tall tree area as their safe home area. They had long upper limbs, short femurs, curved finger bones, and other chimpanzee-like traits that indicate a mixture of arboreal and terrestrial adaptations. Arid climate that intensified in around 2.8 million years ago transformed the mixed habitat of grassy woodland with patches of denser forest, and freshwater springs into the open habitat of mixed grasslands and shrub lands with trees lining rivers and wetlands [16]. At the same time, habitat unpredictability was superimposed on the underlying aridity trend [17]. The open habitat with very few tall trees transformed the early hominins into the early Homo species [6]. The first Homo species, Homo habilis, still retained some body features for climbing trees.

Without the safety of tall trees for young children, old hominins, and pregnant hominins, the early hominins were not adaptable to the open habitat. Bipedalism and division of labor with good communication were good enough for the early hominins to survive in the mixed habitat with the protection of tall trees for about 4 million years. The survival in the open habitat requires three more factors for evolutionary adaptation, consisting of stone tools, controlled fire, and large brain. Without all five factors for evolutionary adaptation to the open habitat, the early hominins became extinct in a short period of time.

The earliest evidence of the use of stone tools dates to 3.3 million years ago in Kenya [18]. The stone tools were made by the early hominins before the oldest known Homo fossil that is 2.8 million years old. It suggests that the early hominins without a large brain had the cognitive and manipulative abilities to carry simple stone toolmaking tasks. For the early hominins, scavenged meat from carcasses could be sliced using sharp edges of flakes, and scavenged bones were broken open with stones to access the marrow inside, The making and the application of simple stone tools by the early hominins did not cause a significant brain expansion. However, there were much more applications of stone tools in the open habitat than in the mixed habitat. As a result, the increase in the applications with new and diverse stone tools in the open habitat was a major reason for the expansion of the brain in the early Homo species. The two early stone tools are Oldowan (2.6 - 1.4 million years ago) and Acheulean (1.6 - 0.25 million years ago). Homo habilis was the hominin who used the tools for most of the Oldowan in Africa. The application of stone tools in hunting tools quickly turned the early Homo species into the hunter specialist group to hunt large animals and the gatherer specialist group to gather plant foods in the open habitat. For the brain expansion of Homo habilis from $500 \mathrm{~cm}^{3}$ to $600 \mathrm{~cm}^{3}$ to improve communication further, Wernicke's area as the new language area was formed in addition to Broca's area for the original language area. Stone tools could be used to grind plants and to sharpen sticks to dig for tubers. The applications of stone tools were also in building protected home base with various 
barricades in the open habitat, preferably by rivers and lakes, and in caves. River and lakes provided water and protection. With the application of stone tools and the brain expansion, the two interdependent specialists became fertile-infertile homemaker-gatherer and fertile explorer-hunter in the open habitat.

Upon further drying, the Middle Homos, such as Homo erectus [19], lived in savanna habitat completely. To hunt large animals also required the increase in body size. Homo erectus had a similar range of body sizes to modern humans. Homo erectus in the middle Homo species was completely terrestrial like humans. Homo erectus transformed the Oldowan into the Acheulean. In contrast to an Oldowan tool resulted from a fortuitous and probably ex tempore operation to obtain one sharp edge on a stone, an Acheulean tool is a planned result of a manufacturing process which required different specialist groups for different parts of tool making process [7]. Theory of mind for tool making specialist groups became an advanced form of theory of mind for advanced specialists with the advanced ability to attribute mental states to different specialists.

Another important factor for survival in the open habitat was fire control. Based on reduced feeding time and molar size, cooking with fire was originated after the evolution of Homo but before or concurrent with the evolution of Homo erectus, which was around 1.9 million years ago [20]. It suggests that fire control occurred as early as 1.9 million years ago by the early Homo species. Fire control allowed the early Homo species to stay warm, cook food, ward off predators, and venture into harsh climates. Cooking with fire forced the early Homo species to live, cook, and eat together, encouraging close large social gathering and interaction. The brain of Homo erectus was doubled to $1100 \mathrm{~cm}^{3}$ by the increase in body size, the environmental adaptation to the open habitat of all different climates, and the social adaptation to the close large social gathering.

The period between 800,000 and 200,000 years ago is the period of the strongest climate fluctuation worldwide. The open habitat became the unstable habitat in East Africa. The unstable habitat caused the fastest evolutionary enlargement of the brain relative to body size, resulting in the emergence of the late Homo species, including Homo sapiens and Neanderthals. Larger brains allowed the late Homo species to process and store information, to plan ahead, and to solve problems. A large brain provided versatile solutions to new and diverse survival challenges in the unstable habitat in East Africa.

The social interaction in late Homo species was complex. Theory of mind for specialists in division of labor turned into theory of mind for mind reading in complex social interaction to enhance cooperation and to detect cheaters. Theory of mind for specialists does not require extensive mind reading. Theory of mind for mind reading allows specialists to appreciate, utilize, and coordinate with one another in terms of mentalization which requires large and complex brains [8]. This sophisticated "metacognitive" ability comes, however, at an evolutionary cost, reflected in a broad spectrum of psychopathological conditions. Extensive research into autistic spectrum disorders has revealed that 
theory of mind for mind reading may be selectively impaired, leaving other cognitive faculties intact [21]. On the neurological side, children and adults with autism show less activation in a previously identified mentalizing network (medial prefrontal cortex, superior temporal sulcus at the temporo-parietal junction and temporal poles) that is associated with theory of mind [22].

\section{Homo Sapiens in the Upper Paleolithic Period}

There was no evidence for extensive religious practice from about 200,000 to about 40,000 years ago [23], so humans were irreligious, basically, because there was no need for religion. According to Agustín Fuentes, religion likely developed from hope and wishful thinking. Believing in the unlikely, the things without material evidence, is a regular part of human existence [24]. This paper posits that human religion is in the form of theory of mind for imaginary specialists in imaginary division of labor under harsh condition. Human specialists and imaginary specialists work together to form imaginary division of labor where imaginary specialists represent the supernatural with supernatural power, guidance, and comfort during the difficult time. It first occurred in the Upper Paleolithic Period [25] [26].

During the Upper Paleolithic Period, a number of sudden temperature drops reduced significantly the area for forest in Europe and Asia. The reduction of forest reduced the food supply, usable timber, and other non-food materials. During the harsh Upper Paleolithic Period, the human society was preoccupied with fertility and vitality for women and men, respectively. The imaginative female figurines and cave paintings appeared during the period. In most cases, the imaginative exaggerated and distorted female figurines were miniature sculptures of well-rounded female nudes with an overemphasis of the fleshy parts of the body (buttocks, stomach and chest). The sexual accent on the female breasts and the posterior are assumed by many to connote signs of fertility. The head and arms are mostly absent with the stress on the middle of the torso. Thighs tend to be exaggerated tapering into smaller legs. The head has no face. According to Alan F. Dixson and Barnaby J. Dixson, these female figurines symbolized and brought the hope for a well-nourished and fertile community facing grim winters and a scarce food supply [9]. In the imaginative cave paints, the animals were mystic large strong animals or mystic animals with horns that symbolized maturation and strength. According to David Lewis-Williams [27], the imaginative cave paintings involved hallucinatory or trance states by drugs or repetitive rhyme. The mystic animal pictures were conceived during the trance states. The mystic powerful animal cave paintings were presented as evidence of spirit journeys previously undertaken. These cave paintings symbolized and brought the hope for a vital and powerful community facing grim winters and a scarce food supply.

The female figurines and the cave painting symbolized the supernatural in terms of fertility for women and vitality for men, respectively. (These religious symbols evolved into fertility goddesses and warrior gods in the civilized society later.) The concept of the supernatural at the time of the Upper Paleolithic Pe- 
riod was considerably different from the current concept of the supernatural. At the time of the Upper Paleolithic Period, the supernatural was immanent supernatural that appeared everywhere as a part of all objects in the world. (The transcendental supernatural was developed later). Anything unexplained or unusual was attributed to the supernatural. Everyone and everything was able equally to become an avatar, the incarnation of the supernatural. The symbols for the immanent supernatural were typically the exaggerated and distorted representation of the real natural objects to represent the unexplained and unusual characteristics of the immanent supernatural, so the symbols represented partly the natural and partly the supernatural. (Symbol is the result of the exaggeration of a specific feature of a real object.) Such symbols brought the immanent supernatural to help people.

During the Upper Paleolithic Period, there was the increasingly sharing of religious symbols for the immanent supernatural among different social groups. The enormous distribution of these female figurines implied a ritualistic exchange system with the figurines playing a central role in intergroup relations [28]. Practicing alternate states of the mind also became community rituals among different social groups, often led by shaman inside or outside of caves. The practicing of the alternate state of mind together promoted unity among different social groups. The sharing of the religious symbols brought about the sharing of survival information and resource among different social groups. The sharing actually improved the fertility and vitality of the groups involved, resulting in the validation of the power of the religious symbols. The result was the rise of the female figurine and cave painting religion. People spent much more energy and time to develop and make such religious symbols for the immanent supernatural, resulting in the Upper Paleolithic Revolution [29] with the rapid development and spread in religious art and the involved skills.

Similar to the Industrial and Neolithic Revolutions, the Upper Paleolithic Revolution during the Upper Paleolithic period represents a short time span when numerous inventions appeared and cultural changes occurred. The revolution comprised new religions, technologies, hunting techniques, human burials, and artistic work. The human society became more cooperative especially in intergroup cooperation beneficial to the survival of humans during this harsh period. The supernatural as religion became a well-established tradition, spreading to all human societies in the world. The supernatural as religion has been ubiquitous in all human societies. Without religion [23], the Neanderthal became extinct during this period.

According to a PET study, theory of mind activates the medial prefrontal node to handle the mental state of the self, the superior temporal sulcus to detect the behavior of other animals and analyzes the goals and outcomes of this behavior, and the inferior frontal region to maintain representations of actions and goals [30]. According to Kapogiannis and Deshpande in the functional MRI study of the brains of both self-declared religious and non-religious individuals, individuals with stronger theory of mind activity were found to be more reli- 
gious [31]. Thinking about God activates brain regions associated with theory of mind [23]. Autistic individuals with problems in imaginative capacities and pretend plays are incapable of theory of mind [33] [34] [35]. Autism with the deficits in theory of mind is linked to lower belief in God [36]. The evolution of theory of mind and different types of theory of mind are described in Table 1.

\section{Theory of Mind Model}

One of the popular tests for theory of mind is the Sally-Anne task by Simon Baron-Cohen [37]. The child who is being tested sits at a table on which two dolls (Anne and Sally) are positioned facing lidded containers (a box and a basket). The experimenter enacts a scenario with the dolls. In this task, Sally first places a marble into her basket and then leaves the scene. Anne then enters, takes the marble out of the basket, and places it into a closed box. The experimenter then asks the participant where Sally will look for the marble. Three groups of children were tested (one at a time)-20 children with autism (experimental group), 14 children with Down's syndrome (control group 1), and 27 typically developing children (control group 2). If the child passes, he or she will point to the basket, understanding that, although this is no longer reality (as the marble is now in the basket), Sally possesses a false-belief that the marble is in the basket because she did not watch Anne move it. To point to the basket is to understand that Sally has her own set of beliefs about the world that differ from the child's (he or she knows where the marble actually is). The task found $85 \%$ of the typically developing children and $86 \%$ of the children with Down's syndrome answered the false-belief question correctly. $80 \%$ of the autistic children fail the false-belief question.

In terms of theory of mind for specialists in division of labor, Sally represents a specialist, marble represented her specialist tool hidden inside nontransparent basket or box, basket and box represent the locations. Sally was a specialist with the marble specialist tool which was originally hidden in the location of basket. After Sally leaves, the marble specialist tool moves to the location of box. When Sally comes back, she comes back to the location of basket with the false-belief that her marble specialist tool is in the location of basket. It is a false-belief only if the nontransparent basket with hidden marble is different from the nontransparent basket without hidden marble as in specialty which is not obvious to

Table 1. The evolution of theory of mind and different types of theory of mind.

\begin{tabular}{cccc}
\hline Species & walking & Habitat & types of theory of mind \\
\hline human-bonobo-chimpanzee ancestor & quadrupedalism & forest & no theory of mind \\
early hominins & bipedalism & mixed & specialists in division of labor (home-exploration) \\
early Homos & bipedalism & open & specialists in division of labor (hunter-gatherer) \\
middle Homos & bipedalism & open & specialists in division of labor (complex production) \\
late Homos & bipedalism & open & mind reading in complex social interactions \\
Homo Sapiens in the Upper Paleolithic Period & bipedalism & harsh & imaginary specialists in division of labor (human-supernatural)
\end{tabular}


outsiders. Without specialty as specialist tool, the nontransparent basket with marble is same as the nontransparent basket without marble in terms of the outward appearance of basket. In the case of the hunter specialist group and the gatherer specialist group in division of labor, a hunter specialist who leaves the group must return to the hunter specialist group instead of any group in the original location. A hunter specialist returns to the gatherer specialist group in the original location is a false specialist with a false-belief.

According to Alan Leslie [38], "Theory-of-Mind Mechanism" (ToMM) receives as input information about the past and present behavior of other people and utilizes this information to compute their probable psychological states. The outputs of ToMM are descriptions of psychological states in the form of metarepresentations or M-representations, which involve the descriptions of the behavior of agent, including 1) an agent, 2) an informational relation that specifies the agent's attitude (pretending, believing, desiring, and so forth), 3) an aspect of reality that grounds the agent's attitude, 4) the content of the agent's attitude. In theory of mind for specialists in division of labor, M-representation represents the description of the specialty of a specialist in division of labor.

According to Alan Leslie [39], the other part of theory of mind is inhibitory "Selection Processor" (SP) to inhibit default attribution and select an alternative nonfactual content for the belief. Thus 3-year-old fail standard false-belief tasks because they possess the ToMM but not yet the inhibitory SP. According to Leslie and Thaiss [40], the ToMM/SP model can account for these findings: normal 3 -year-old possess the ToMM but not yet SP; autistic children are impaired in ToMM but not in SP; normal 4-year-old possess both the ToMM and an adequate SP. In theory of mind for specialists in division of labor, ToMM represents the description of the specialty of a specialist, and SP represents the selection processor to inhibit the default location of a specialist and to select the nonfactual location of true location where the specialist should locate. The combination of the proper description of the specialty of a specialist in ToMM and the proper selection of true location where the specialist should locate in SP provides correct division of labor.

Theory of mind in terms of division of labor is basically same as the pretend play to assign arbitrarily different invisible specialties to different groups with similar outward appearances. Theory of mind for specialists in division of labor turns into theory of mind for mind reading in complex social interaction. Theory of mind for mind reading in complex social interaction follows the Leslie's ToMM/SP model. Theory of mind for imaginary specialists in imaginary division of labor follows theory of mind for specialists in division of labor.

\section{The Model for Self-Awareness in the Mirror Self-Recognition (MSR) Test}

The model for self-awareness in the mirror self-recognition test is similar to theory of mind model. In the mirror self-recognition (MSR) test [41], an animal under anesthetized is marked on an area of the body the animal cannot normally 
see. The recovered animal is given access to a mirror. If the animal then touches or investigates the mark, the animal perceives the reflected image as itself, rather than of another animal. The animal passes the mirror self-recognition test.

Similar to the Leslie's ToMM/SP model for theory of mind, the proposed model for self-awareness is the self-awareness mechanism (SAM)/SP model. "Self-awareness Mechanism" (SAM) receives as input information about the objects of senses (sight, sound, smell, taste, and touch) to compute self and non-self. The outputs of SAM are the descriptions of different states of self from different senses in form of metarepresentations (M-representations) as described by Gerald $M$. Edelman for the sensory integration of various separable underlying mechanisms of self-awareness [42] [43] [44]. All animals have SAM. Humans use mostly sight and touch for SAM. Self is visible and touchable all the time, while non-self is usually untouchable. The people who fail SAM have body integrity dysphoria which is a psychiatric condition characterized by a persistent desire to acquire physical disability (e.g., amputation or paraplegia) to one particular healthy part of the body as if the particular healthy part of the body is not a part of the body [45].

The other part of self-awareness model is inhibitory "Selection Processor" (SP) to inhibit untouchable sighted self-copy image on the mirror as non-self, and to select untouchable sighted self-copy image on the mirror as self. Monkeys do not pass the mirror self-recognition test, while great apes pass the mirror self-recognition test [46]. This paper proposes that SP involves the sight-touch override where the determination of either sight or touch can occasionally override the determination of the other. Self is visible and touchable all the time, while non-self is usually untouchable. As a result, with the sight-touch override, the untouchable visible self-copy image on the mirror can still be self determined by sight to override the determination by touch. Without the sight-touch override, the untouchable visible self-copy image on the mirror looks like self, but cannot be self determined by sight without overriding the determination by touch. The evolutionary origin of the sight-touch override is from the difference of safety determination between the safety determined by sight and the safety determined by touch. During the locomotion from branch to branch for a light-weight monkey, the safety of a branch determined by sight usually is in agreement with the safety determined by touch, so the movement is very quick without hesitation, such as leaping from branch to branch. During the locomotion from branch to branch for a heavy-weight great ape, the safety of a branch determined by sight occasionally is not in agreement with the safety determined by touch, so the locomotion is slow and deliberate by constantly checking the safety determined by touch in brachiation [47]. The result is that great apes have the sight-touch override, while monkeys do not have the sight-touch override. As a result, great apes pass the mirror self-recognition test, while monkeys do not pass the mirror self-recognition test. Intelligent animals can be trained to pass the mirror self-recognition test. B. F. Skinner found that pigeons passed a highly modified mirror self-recognition test after extensive training [48]. 
Masanori Kohda et al. found that cleaner wrasse passed the mirror self-recognition test [49]. Cleaner wrasse lives on coral reefs and specializes in finding food by nibbling parasites and dead skin off the bodies of larger fish. It's a dangerous life, and cleaner wrasses have to be savvy to avoid being eaten themselves. This dangerous task of finding food forces cleaner wrasse to check constantly the safety determined by sight by the safety determined by touch which can easily alert the targeted fish. The result is the sight-touch override for cleaner wrasse to pass the mirror self-recognition test.

In conclusion, the mirror self-recognition test is not a test for the evolutionary acquisition of self-awareness which all animals have to distinguish self and non-self. The mirror self-recognition test is a test for the sight-touch override, because a mirror allows the self determined by sight to override the self determined by touch. On the other hand, some stroke patients at times become certain that a paralyzed limb was not their own, and even certain ownership over other people's appendages [50]. In such cases, the self determined by touch overrides the self determined by sight. The reference literatures for each topic are described in Table 2.

Table 2. The reference literatures for each topic.

\begin{tabular}{cc}
\hline \multicolumn{1}{c}{ Topics } & References \\
\hline Theory of mind in general & {$[1][2][3]$} \\
Theory of mind in early hominins & {$[4][5][10]-[15]$} \\
Theory of mind in early Homos & {$[6][16][17][18]$} \\
Theory of mind in middle Homos & {$[7][19][20]$} \\
Theory of mind in late Homos & {$[8][21][22]$} \\
Theory of mind in Homo Sapiens in the Upper Paleolithic Period & {$[9][23]-[37]$} \\
Theory of mind model & {$[38][39][40]$} \\
\hline
\end{tabular}

\section{Summary and Conclusion}

In summary, this paper proposes that the evolution of theory of mind that occurs only in human starts from the beginning of the human evolution to form hominins through bipedalism and the mixed habitat. The feet of the early hominins were still adapted for grasping trees rather than walking for long distances and running fast on the ground. The early hominins lived in the mixed habitat of grassy woodland with patches of denser forest, and freshwater springs. The difficulty of walking in the mixed habitat leads to division of labor for the home specialist group (small children, old people, and mothers with small children, and pregnant women) in the safe forest area and the exploration specialist group (young people without the care of small children) in the dangerous open area. The different tasks, attitudes, and mentalities in different specialist groups produce theory of mind as the ability to attribute different mental states to different specialist groups. (Uniformity of mind instead of theory of mind is for general- 
ists without division of labor).

The early Homo species with the open habitat developed theory of mind for hunter specialist group and gatherer specialist group. The middle Homo species with complex stone tools developed theory of mind for the cooperative specialist groups in the large production of complex stone tools. The late Homo species with complex social interaction developed theory of mind for mind reading to enhance cooperation and to detect cheaters in complex social interaction. For religion, the unusually harsh Upper Paleolithic Period developed theory of mind for imaginary specialists in terms of supernatural power, guidance, and comfort.

In the Sally-Anne task by Simon Baron-Cohen, Sally represents a specialist in division of labor, and marble represents her hidden specialty in the locations of nontransparent basket and box. In the Leslie's ToMM/SP model, M-representation in ToMM describes a hidden specialty in division of labor, and SP inhibits a default specialty, and selects an alternative nonfactual hidden specialty. Theory of mind in terms of division of labor is basically same as the pretend play that assigns arbitrarily different invisible specialties to different groups with similar outward appearances. Theory of mind for specialists in division of labor turns into theory of mind for mind reading in complex social interactions.

This paper proposes that self-awareness in the mirror self-recognition test involves the sight-touch override where the determination of either sight or touch can occasionally override the determination of the other. Self is visible and touchable all the time, while non-self is usually untouchable. As a result, with the sight-touch override, the untouchable visible self-copy image on the mirror can still be self determined by sight to override the determination by touch. Without the sight-touch override, the untouchable visible self-copy image on the mirror looks like self, but cannot be self determined by sight without overriding the determination by touch.

In conclusion, uniformity of mind for generalist without division of labor where all members work in the same group is for nonhuman primates. Theory of mind involves home group/exploration group (started from Ardipithecus ramidus 4.4 mya), hunter group/gatherer group (started from Homo habilis 2.5 mya), stone tool production groups (started from Homo erectus 1.9 mya), mind reading in complex social interaction (started from the late Homo species 200 kya), and imaginary group/human group (started from the Upper Paleolithic period $40 \mathrm{kya}$ ). Therefore, the three types of theory of mind are for specialists in division of labor, mind reading in complex social interaction, and imaginary specialists in imaginary division of labor under harsh condition.

\section{Conflicts of Interest}

The author declares no conflicts of interest regarding the publication of this paper.

\section{References}

[1] Heyes, C. (2015) Animal Mindreading: What's the Problem? Psychonomic Bulletin 
\& Review, 22, 313-327. https://doi.org/10.3758/s13423-014-0704-4

[2] Premack, D. and Woodruff, G. (1978) Does the Chimpanzee Have a Theory of Mind? Behavioral and Brain Sciences, 1, 515-526.

https://doi.org/10.1017/S0140525X00076512

[3] Tsoukalas, I. (2018) Theory of Mind: Towards an Evolutionary Theory. Evolutionary Psychological Science, 4, 38-66. https://doi.org/10.1007/s40806-017-0112-X

[4] Chung, D. (2016) The Basic Principles of Kin Sociality and Eusociality: Human Evolution. Natural Science, 8, 8-19. https://doi.org/10.4236/ns.2016.81002

[5] White, T., et al. (2009) Ardipithecus ramidus and the Paleobiology of Early Hominins. Science, 326, 75-86. https://doi.org/10.1126/science.1175802

[6] Antón, S. (2012) Early Homo: Who, When, and Where. Current Anthropology, 53, 279. https://doi.org/10.1086/667695

[7] Faisal, A., Stout, D., Apel, J. and Bradley, B. (2010) The Manipulative Complexity of Lower Paleolithic Stone Tool-Making. PLoS ONE, 5, e13718.

https://doi.org/10.1371/journal.pone.0013718

[8] Fonagy, P., Gergely, G., Jurist, E. and Target, M. (2002) Affect Regulation, Mentalization and the Development of the Self. Other Press, New York.

[9] Dixson, A. and Dixson, B. (2011) Venus Figurines of the European Paleolithic: Symbols of Fertility or Attractiveness? Journal of Anthropology, 2011, Article ID: 569120. https://doi.org/10.1155/2011/569120

[10] Carvalho, S., et al. (2012) Chimpanzee Carrying Behaviour and the Origins of Human Bipedality. Current Biology, 22, R180-R181.

https://doi.org/10.1016/j.cub.2012.01.052

[11] Lovejoy, C. (2009) Reexamining Human Origins in Light of Ardipithecus ramidus. Science, 326, 74e71-74e78. https://doi.org/10.1126/science.1175834

[12] Gardner, R., Garner, B. and Van Cantfort, T. (1989) Teaching Sign Language to Chimpanzees. State University of New York Press, New York.

[13] Corballis, M. (1999) The Gestural Origins of Language. American Scientist, 87, 138-145. https://doi.org/10.1511/1999.2.138

[14] Hickok, G., Bellugi, U. and Klima, E.S. (1996) The Neurobiology of Sign Language and Its Implications for the Neural Basis of Language. Nature, 381, 699-702. https://doi.org/10.1038/381699a0

[15] Gibbons, A. (2009) A New Kind of Ancestor: Ardipithecus Unveiled. Science, 326, 36-40. https://doi.org/10.1126/science.326.5949.36

[16] DiMaggio, E., et al. (2015) Paleoanthropology. Late Pliocene Fossiliferous Sedimentary Record and the Environmental Context of Early Homo from Afar, Ethiopia. Science, 347, 1355-1359. https://doi.org/10.1126/science.aaa1415

[17] Anton, S., Potts, R. and Aiello, L. (2014) Evolution of Early Homo: An Integrated Biological Perspective. Science, 345, Article ID: 1236828. https://doi.org/10.1126/science.1236828

[18] Harmand, S., et al. (2015) 3.3-Million-Year-Old Stone Tools from Lomekwi 3, West Turkana, Kenya. Nature, 521, 310-315. https://doi.org/10.1038/nature14464

[19] Herries, A., et al. (2020) Contemporaneity of Australopithecus, Paranthropus, and Early Homo Erectus in South Africa. Science, 368, eaaw7293. https://doi.org/10.1126/science.aaw7293

[20] Organ, C., et al. (2011) Phylogenetic Rate Shifts in Feeding Time during the Evolu- 
tion of Homo. Proceedings of the National Academy of Sciences, 108, 14555-14559. https://doi.org/10.1073/pnas.1107806108

[21] Brüne, M. and Brüne-Cohrs, U. (2006) Theory of Mind-Evolution, Ontogeny, Brain Mechanisms and Psychopathology. Neuroscience and Biobehavioral Reviews, 30, 437-455. https://doi.org/10.1016/j.neubiorev.2005.08.001

[22] Castelli, F., Frith, C., Happé, F. and Frith, U. (2002) Autism, Asperger Syndrome and Brain Mechanisms for the Attribution of Mental States to Animated Shapes. Brain, 125, 1839-1849. https://doi.org/10.1093/brain/awf189

[23] Wunn, I. (2000) Beginning of Religion. Numen, 47, 417-453. https://doi.org/10.1163/156852700511612

[24] Fuentes, A. (2017) The Creative Spark: How Imagination Made Humans Exceptional. Penguin, London.

[25] Chung, D. (2016) The Human Religious Evolution. Open Journal of Social Sciences, 4, 75-90. https://doi.org/10.4236/jss.2016.43013

[26] Chung, D. (2019) The Evolution of Theisms: The Four Technological Revolutions and the Four Theistic Revolutions. Open Journal of Social Sciences, 7, 213-242. https://doi.org/10.4236/jss.2019.74018

[27] Lewis-Williams, D. (2002) The Mind in the Cave: Consciousness and the Origins of Art. Thames \& Hudson, London.

[28] Cunliffe, B. (2001) The Oxford Illustrated History of Prehistoric Europe. Oxford University Press, Oxford.

[29] Bar-Yosef, O. (2002) The Upper Paleolithic Revolution. Annual Review of Anthropology, 31, 363-393. https://doi.org/10.1146/annurev.anthro.31.040402.085416

[30] Calarge, C. andreasen, N. and O’Leary, D. (2003) Visualizing How One Brain Understands Another: A PET Study of Theory of Mind. American Journal of Psychiatry, 160, 1954-1964. https://doi.org/10.1176/appi.ajp.160.11.1954

[31] Kapogiannis, D., et al. (2014) Brain Networks Shaping Religious Belief. Brain Connectivity, 4, 70-79. https://doi.org/10.1089/brain.2013.0172

[32] Kapogiannis, D., et al. (2009) Cognitive and Neural Foundations of Religious Belief. Proceedings of the National Academy of Sciences, 106, 4876-4881. https://doi.org/10.1073/pnas.0811717106

[33] Scott, F. and Baron-Cohen, S. (1996) Imagining Real and Unreal Objects: Evidence of a Dissociation in Autism. Journal of Cognitive Neuroscience, 8, 400-411. https://doi.org/10.1162/jocn.1996.8.4.371

[34] Angus, D., et al. (2014) Limitations in Social Anticipation are Independent of Imaginative and Theory of Mind Abilities in Children with Autism But Not in Typically Developing Children. Autism, 19, 604-612.

https://doi.org/10.1177/1362361314537911

[35] Chan, P., et al. (2016) Theory of Mind Deficit Is Associated with Pretend Play Performance, But Not Playfulness, in Children with Autism Spectrum Disorder. Hong Kong Journal of Occupational Therapy, 28, 43-52. https://doi.org/10.1016/j.hkjot.2016.09.002

[36] Norenzayan, A., Gervais, W. and Trzesniewski, K. (2012) Mentalizing Deficits Constrain Belief in a Personal God. PLoS ONE, 7, e36880. https://doi.org/10.1371/journal.pone.0036880

[37] Baron-Cohen, S., Leslie, A. and Frith, U. (1985) Does the Autistic Child Have a "Theory of Mind". Cognition, 21, 37-46. 
https://doi.org/10.1016/0010-0277(85)90022-8

[38] Leslie, A.M. (1994) ToMM, ToBy, and Agency: Core Architecture and Domain Specificity. In: Hirschfeld, L. and Gelman, S., Eds., Mapping the Mind: Domain Specificity in Cognition and Culture, Cambridge University Press, Cambridge, 119-148. https://doi.org/10.1017/CBO9780511752902.006

[39] Leslie, A. and Polizzi, P. (1998) Inhibitory Processing in the False Belief Task: Two Conjectures. Development Science, 1, 247-254. https://doi.org/10.1111/1467-7687.00038

[40] Leslie, A. and Thaiss, L. (1992) Domain Specificity in Conceptual Development: Neuropsychological Evidence from Autism. Cognition, 43, 225-251. https://doi.org/10.1016/0010-0277(92)90013-8

[41] Gallup, G. (1970) Chimpanzees: Self Recognition. Science, 167, 86-87. https://doi.org/10.1126/science.167.3914.86

[42] Edelman, G. and Tononi, G. (2000) A Universe of Consciousness. Basic Books, New York.

[43] Edelman, G. and Gally, J. (2013) Reentry: A Key Mechanism for Integration of Brain Function. Frontiers in Integrative Neuroscience, 7, 63. https://doi.org/10.3389/fnint.2013.00063

[44] Hecht, E., et al. (2017) A Neuroanatomical Predictor of Mirror Self-Recognition in Chimpanzees. Social Cognitive and Affective Neuroscience, 12, 37-48.

https://doi.org/10.1093/scan/nsw159

[45] Brugger, P. and Lenggenhager, B. (2014) The Bodily Self and Its Disorders: Neurological, Psychological and Social Aspects. Current Opinion in Neurology, 27, 644-652. https://doi.org/10.1097/WCO.0000000000000151

[46] Suárez, S. and Gallup, G. (1981) Self-Recognition in Chimpanzees and Orangutans, but Not Gorillas. Journal of Human Evolution, 10, 175-188. https://doi.org/10.1016/S0047-2484(81)80016-4

[47] Gebo, D. (1996) Climbing, Brachiation, and Terrestrial Quadrupedalism: Historical Precursors of Hominid Bipedalism. The American Journal of Physical Anthropology, 101, 55-92. https://doi.org/10.1002/(SICI)1096-8644(199609)101:1<55::AID-AJPA5>3.0.CO;2-C

[48] Epstein, L., Skinner, R. and Skinner, B. (1981) Self-Awareness in the Pigeon. Science, 212, 695-696. https://doi.org/10.1126/science.212.4495.695

[49] Kohda, M., et al. (2019) If a Fish Can Pass the Mark Test, What Are the Implications for Consciousness and Self-Awareness Testing in Animals? PLoS Biology, 17, e3000021. https://doi.org/10.1371/journal.pbio.3000021

[50] Gallagher, I. (2000) Philosophical Conceptions of the Self: Implications for Cognitive Science. Trends in Cognitive Sciences, 4, 14-21. https://doi.org/10.1016/S1364-6613(99)01417-5 